\title{
В.Л. Лозицкий
}

А.Н. Яковлев²

Полесский государственный университет

Пинск. Республика Беларусь

\section{Дидактическая роль электронного учебно- методического комплекса на первой ступени высшего образования (на примере учебной дисциплины «Спортивно-педагогическое совершенствование»)}

\begin{abstract}
Статья посвящена исследованию проблематики разработки и системного применения электронных учебно-методических комплексов (ЭУМК) на первой ступени высшего профессионального образования. На примере учебной дисциплины «Спортивно-педагогическое совершенствование» авторы обосновывают теоретические практико-ориентированные положения, реализация которыхпозволит создавать и внедрять в целостный педагогический процесс в высшей профессиональной школе эффективные высокотехнологичные информационные продукты учебного назначения. В разработанной авторами функциональной модели электронного учебно-методического комплекса реализован модульный принцип выстраивания архитектуры ЭУМК, что позволяет оперативно и гибко решать проблему соответствия контента создаваемого образовательного продукта в условиях изменения содержания образования по учебной дисциплине. Результаты экспериментальной деятельности по реализации технологического и дидактического подходов в исследованиях по интеграции средств информационно-коммуникационных технологий в учебный процесс, осуществляемых в учреждении образования «Полесский государственный университет», показывают, что их использование в практике обучения специалистов в сфере физической культуры и спорта позволяет достичь высоких образовательных результатов.
\end{abstract}

Ключевые слова и словосочетания: высшее профессиональное образование, учреждение высшего образования, электронный учебно-методический комплекс, информационнокоммуникационные технологии, специфика обучения, модуль.

\footnotetext{
1 Лозицкий Вячеслав Леонтьевич - канд. пед. наук, доцент, доцент кафедры гуманитарных наук, философии и права Полесского государственного университета; e-mail: bakalaur@tut.by.

2 Яковлев Анатолий Николаевич - канд. пед. наук, доцент, доцент кафедры оздоровительной и адаптивной физической культуры Полесского государственного университета; e-mail: Yak-33-c1957@mail.ru.
} 
V.L. Lozitsky ${ }^{1}$

A.N. Yakovlev ${ }^{2}$

Polesye State University

Pinsk. Belarus

\title{
Didactic role of an electronic educational and methodical complex at the first step of the higher education (on the example of the subject matter «Pedagogics and psychology of the higher school»)
}

\begin{abstract}
Article is devoted to a research of a perspective of development and system application of electronic educational and methodical complexes at the first step of higher education. On the example of a subject matter "Sports and pedagogical improvement" authors prove theoretical and practical provisions which implementation will allow to create and introduce in complete pedagogical process at the higher vocational school effective hi-tech information products of educational appointment. In the functional model of an electronic educational and methodical complex developed by authors it is realized modular the principle of forming of architecture of that allows to solve quickly and flexibly a problem of compliance of content of the created educational product in the conditions of change of content of education on a subject matter. Results of experimental activities for realization of technological and didactic approaches in the researches on integration of means of information and communication technologies into educational process conducted in establishment of education "Polessky State University", show that their use in practice of training of experts in the sphere of physical culture and sport allows to achieve high educational results.
\end{abstract}

Keywords: higher education, institution of higher education, electronic educational and methodical complex, information and communication technologies, specifics of training, module.

\section{Введение}

Решение совокупности задач современного вузовского образования в своей прогнозируемой результирующей части предполагает разработку соответствующих средств обучения, адаптированных содержанию современного образования и существующим дидактическим подходам. Модернизационные процессы в сфере высшего профессионального образования в своей остроте актуализируют проблематику исследований в области разработки и применения эффективного высокотехнологичного дидактического инструментария, позволяющего в соединении с используемыми методами обучения повысить качество подготовки специалистов выпускников вузов. Создание и интеграция в педагогическую практику высшей профессиональной школы средств информационно-коммуникационных технологий позволят поднять уровень самостоятельной учебной деятельности студентов с

\footnotetext{
${ }^{1}$ Vyacheslav L. Lozitsky - Candidate of Pedagogical Sciences, Associate Professor of the Chair of humanities, philosophies and rights of the Polesye State University; e-mail: bakalaur@tut.by.

2 Anatoliy N. Yakovlev - Candidate of Pedagogical Sciences, Associate Professor of the Chair of the improving and adaptive physical culture of the Polesye State University; e-mail: Yak-33-c1957@mail.ru.
} 
учетом специфики получения образования в сфере физической культуры и спорта. В свою очередь, систематизация и обобщение результатов экспериментальной деятельности в данной области позволит рельефно обозначить важные тенденции, учет которых целесообразен в рамках продолжения эффективных разработок, ориентированных на потребности высшей профессиональной школы (в том числе, первой ее ступени).

\section{Состояние вопроса}

Уровень исследованности проблематики разработки и интеграции средств информационно-коммуникационных технологий в образование, достигнутый в работах Н.В. Агеева, А.И. Архиповой, В.П. Беспалько, В.А. Воробьева, Ю.И. Воротницкого, Е.И. Дмитриева, Ю.Г. Древса, А.И. Жука, Д.В. Иуса, И.В. Кочубей, А.В. Макарова, П.А. Мандрика, О.А. Сосновского, А.М. Филипцова $[1-5,8]$, позволяет учесть специфику создания электронных учебно-методических комплексов в аспекте их системного применения в процессе обучения студентов, получающих высшее профессиональное образование в сфере физической культуры и спорта. Рассмотрение вопросов разработки и системного применения ЭУМК в учебном процессе в существующих фундаментальных и прикладных исследованиях способствует активизации процесса создания функциональных моделей электронных образовательных ресурсов и интеграции их в практику обучения. Выделение при этом ценностно-целевого компонента в содержании образования, а также когнитивных моделей субъект-субъектных взаимодействий участников целостного педагогического процесса позволяет не только вычленить дидактическую роль создаваемых ЭУМК, но и определить организационно-методические условия их эффективного применения в учреждениях высшего образования. В соответствии с Кодексом Республики Беларусь об образовании [6] на первой ступени высшего образования реализуется образовательная программа, призванная обеспечить профессиональную подготовку студентов, сформировать у них соответствующие личностно значимые компетенции. Данные аспекты учитывались при инициировании темы научного исследования.

Результаты экспериментальной деятельности по реализации технологического и дидактического подходов в исследованиях по интеграции средств информационно-коммуникационных технологий в учебный процесс, осуществляемых в учреждении образования «Полесский государственный университет» с 2013 г., показывают, что их использование в практике обучения специалистов в сфере физической культуры и спорта позволяет достичь высоких образовательных результатов.

Цель исследования. Теоретико-методологическое обоснование разработки и системного применения инструментария электронного учебно-методического комплекса в процессе подготовки специалистов в сфере физической культуры и спорта на первой ступени высшего профессионального образования.

Предмет исследования. Процесс разработки и практического применения высокотехнологичного дидактического инструментария электронного учебнометодического комплекса по учебной дисциплине «Спортивно-педагогическое 
совершенствование» в условиях модернизационных процессов в сфере высшего профессионального образования, позволяющего в системе методов обучения эффективно решать актуализируемые социумом образовательные задачи.

Материал и методы исследования. Сравнительно-сопоставительный анализ научной и специальной литературы.

Результаты исследований и их обсуждение. В рамках политики методического обеспечения процесса обучения, осуществляемой в Полесском государственном университете, а также мероприятий, реализуемых по теме научно-исследовательской работы на кафедрах гуманитарных наук, философии и права, а также оздоровительной и адаптивной физической культуры создана и интегрирована в учебный процесс функциональная модель ЭУМК по учебной дисциплине «Спортивнопедагогическое совершенствование» [7]. Практическая реализация разработанной модели осуществлена с помощью технологического и дидактического потенциала облачного сервиса образовательной платформы «MOODLE» (http://moodle.edu. by). Авторами учтена проблематика определения дидактической роли, а также критериев структурирования и содержательного наполнения компонентов ЭУМК, ориентированных в своей направленности на формирование и развитие у студентов соответствующих компетенций, определяемых содержанием образовательного стандарта и учебной программы по дисциплине. Представляется недопустимым включение в структуру ЭУМК компонентов, ориентированных на воспроизведение определенных объемов учебной информации без отработки умений ее анализа и систематизации. Исходя из специфики организации процесса обучения на первой ступени высшего образования, дидактический и технологический потенциал включаемых в ЭУМК компонентов должен в своей господствующей направленности ориентироваться на поддержку проблемно-поисковой и исследовательской деятельности в рамках компетентностного подхода в противовес традиционному репродуктивно-знаниевому обучению в режиме его исключительно демонстрационного сопровождения. В данной взаимосвязи важной проблемой, решаемой авторами-практиками при создании эффективно применяемого ЭУМК, являются конструирование и отбор содержания учебного материала с учетом требований образовательного стандарта и учебной программы.

Авторами учтено, что основной целью освоения студентами дисциплины «Спортивно-педагогическое совершенствование» является формирование психолого-педагогических компетенций, обеспечивающих эффективное решение профессиональных и социально-личностных проблем спортивно-тренировочной деятельности в учреждении высшего образования. Изучение данной дисциплины в сочетании с дисциплинами предметного цикла, прежде всего теория и методика физического воспитания и теория спорта, направлено на решение педагогических и практических задач, связанных с формированием целостного представления о профессиональной деятельности специалистов в области физической культуры и спорта.

Практико-ориентированным аспектом в обучении студентов является выработка компетенций в педагогически правильном и научно обоснованном использовании комплекса средств, методов и форм работы, применяемых в избранном виде спорта. 
Это позволит сыграть особую роль в формировании у выпускников учреждения высшего образования психолого-педагогической компетентности, которая будет востребована как в педагогической, так и в других профессиональных областях и обеспечит продуктивное разрешение разнообразных социально-профессиональных задач, включая управленческие, коммуникативные, акмеологические. Эффективное решение данных задач разнонаправленно позволяет обеспечивать применение электронного учебно-методического комплекса по учебной дисциплине как студентами, так и преподавателями.

ЭУМК «Спортивно-педагогическое совершенствование», применяемый на первой ступени высшего образования, целесообразно рассматривать в качестве предметного информационного образовательного ресурса, предназначенного для эффективного дидактического обеспечения организации и осуществления процесса обучения студентов. Свою дидактическую роль ЭУМК выполняет посредством функциональной реализации технологического и дидактического потенциала. Программный продукт учебного назначения обеспечивает непрерывность и полноту дидактического цикла процесса обучения, содержит организационные и систематизированные теоретические, практические, контролирующие материалы, оптимизированные по отношению к разработанным научно-методическим основам их создания и системного применения на первой ступени высшего образования. В качестве таковых основ нами определены следующие:

- дидактический подход к пониманию сущности электронных компонентов УМК, связанный с учетом их технологических и дидактических свойств и обусловленный особенностями процесса познания во взаимосвязи со спецификой предметного обучения на первой ступени высшего образования;

- методическиепринципы системного применения электронных компонентов ЭУМК;

- методические условия создания и системного применения ЭУМК с учетом дидактической роли, выполняемой его структурными компонентами;

- критерии содержательного наполнения электронных компонентов ЭУМК с учетом основных содержательных линий образовательного стандарта, компонентов учебных знаний и соответствующих формируемых профессиональных компетенций студентов.

Авторами создателями ЭУМК учтено, что задачи изучения дисциплины «Спортивно-педагогическое совершенствование» определяются требованиями к овладению студентами обобщенными знаниями и умениями, лежащими в основе психолого-педагогических компетенций, характеризующих психолого-педагогическую компетентность выпускника вуза. Психолого-педагогические компетенции, которые формируются в процессе освоения дисциплины «Спортивно-педагогическое совершенствование» на первой ступени высшего образования, включают:

- компетенции, относящиеся к изучению и учету возрастных, гендерных и психологических особенностей студентов вуза, механизмов их мотивации;

- компетенции, направленные на организацию и осуществление процесса обучения и спортивно-тренировочной деятельности, активизацию самостоятельной работы студентов; 
- компетенции, обеспечивающие организацию процесса воспитания студентов;

- компетенции, обеспечивающие овладение эффективными педагогическими технологиями и совершенствование учебно-методического обеспечения образовательного процесса (в том числе, с использованием средств информационно-коммуникационных технологий);

- компетенции, направленные на продуктивное решение коммуникативных проблем педагогической деятельности;

- компетенции, связанные с проведением педагогического мониторинга, управлением образовательным процессом, учреждением образования в целом, развитием студенческого коллектива, а также с менеджментом качества образования;

- компетенции, обусловливающие освоение педагогических инноваций в сфере физической культуры и спорта;

- компетенции непрерывного профессионального самообразования и личностного самосовершенствования.

Выделенные авторами ЭУМК целе-задачные аспекты позволили выстроить структуру и содержание практической модели электронного образовательного ресурса с учетом многокомпонентного состава предлагаемых к усвоению учебных знаний. К компонентам состава учебных знаний, определяющих содержательное наполнение ЭУМК «Спортивно-педагогическое совершенствование», относятся:

- теоретические (включают в себя понятия разной степени обобщения, существенные причинно-следственные связи, закономерности развития, теоретические выводы, содержащие оценки фактов, обобщенную характеристику их сущностных признаков, причин, следствий и значения);

- методологические (знания о методах, процессе познания, о конкретных методах науки и различных способах деятельности);

- оценочные (ознакомление с различными точками зрения на события, явления и процессы).

Представленный многокомпонентный состав учебных знаний учтен в структуре и содержании практической модели электронного образовательного ресурса, в тематических линиях модулей. К таковым линиям в ЭУМК по учебной дисциплине отнесем:

- общие основы спортивной педагогики и психологии;

- педагогические основы процесса обучения в области физической культуры и спорта;

- основные методы, формы и средства обучения в учреждении образования;

- технологизацию и информатизацию образовательного процесса в учреждении образования;

- теоретико-практические основы физического воспитания в школе;

- педагогический менеджмент в системе образования.

Как доказывает практика создания и системного применения электронных образовательных ресурсов, неприемлемой является интеграция в образовательный процесс предметных ЭУМК, дидактическая роль которых на первой ступени высшего образования сводилась бы к жесткому навязыванию той или иной траектории 
обучения студентов. Ведь гибкость и способность предлагать преподавателю элементы для создания неповторимой и индивидуальной модели учебного занятии, а студентам - ресурсы для осуществляемой самостоятельной учебной деятельности являются важным методическим требованием к применению электронных компонентов учебно-методического комплекса. В такой взаимосвязи педагогически оправданным видится определение дидактической роли ЭУМК на первой ступени высшего образования в управлении процессом усвоения студентами многокомпонентного состава учебных знаний, а также в формировании их профессиональных психолого-педагогических компетенций при осуществлении учебной деятельности на всех ее этапах и при необходимой алгоритмизации.

Обозначенный подход в трактовке дидактической роли предметного ЭУМК позволил реализовать модульный принцип выстраивания структуры электронного образовательного ресурса по учебной дисциплине «Спортивно-педагогическое совершенствование». Модуль ЭУМК - это структурный компонент электронного образовательного ресурса, относительно самостоятельная организационно-содержательная единица системы обучения, выполняющая конкретную дидактическую роль.

Реализованная на практике модель предметного электронного образовательного ресурса включает в себя следующие модули:

- нормативный (содержит документацию, определяющую содержание высшего образования на первой ступени в данной предметной области, и иные программнопланирующие и учебно-методические документы: образовательный стандарт; учебные программы, перечень рекомендуемых учебных изданий и информационноаналитических материалов, вопросы зачета/экзамена);

- справочно-информационный (элементы дидактического обеспечения организации и проведения учебных занятий: тезаурус - понятийно-терминологическое структурирование учебного материала; электронный глоссарий, включающий в себя элементы теоретического знания - понятийно-терминологический апарат; электронная хрестоматия);

- теоретический (электронные материалы лекционного курса, обеспечивающие теоретическое изучение дисциплины в объеме, определяемом требованиями образовательного стандарта и предметной программы);

- практический (включает материалы семинарских/практических занятий);

- контрольно-диагностический (варианты тематических и обобщающих комплексов разноуровневых тестовых заданий - электронный инструментарий, позволяющий осуществлять педагогическую диагностику и контроль с целью определения соответствия результатов учебно-познавательной деятельности студентов требованиям образовательного стандарта и учебной программы).

Содержательное наполнение модулей в реализованной модели предметного ЭУМК оптимизировано с учетом специфики содержания, дидактической направленности и функции того или иного элемента модуля. Как показывает практика создания электронных учебно-методических комплексов, их модульное структурирование позволяет сохранить открытость и адаптивность электронного 
образовательного ресурса с учетом ситуации возможного изменения структуры и содержания образования, требований и содержания образовательного стандарта, а также программно-методической документации.

В качестве дидактических свойств модулей - электронных компонентов ЭУМК, применяемого на первой ступени высшего образования, целесообразно выделить следующие:

- управляемость процессом обучения (возможность управления деятельностью субъектов обучения);

- обеспечение системного подхода к процессу обучения (применение компонентов ЭУМК в сочетании с традиционными средствами обучения на всех этапах организации учебной деятельности студентов при ее алгоритмизации);

- способность достижения полноты усвоения знаний (организация процесса обучения предусматривает овладение содержанием учебного материала в соответствии с заданным уровнем его усвоения);

- индивидуализация обучения (организация учебного процесса, при которой студент свободно выбирает и осуществляет нужный ему вид деятельности в приемлемом для него темпе);

- диагностирование результатов процесса обучения (возможность автоматизированного учета учебных достижений и динамики их изменения с помощью контрольно-измерительного инструментария ЭУМК).

В силу своего совокупного дидактического и технологического потенциала ЭУМК по учебной дисциплине «Спортивно-педагогическое совершенствование» является действенным средством обеспечения процесса организации и осуществления обучения на первой ступени высшего образования.

Его преимуществами являются:

- концентрированное наличие сгруппированного нормативного и дидактического материала;

- оптимизированность компонентов и гибкость структуры ЭУМК по отношению к содержанию образования и положениям учебной программы;

- технологическая интегрируемость в процесс обучения;

- наличие обратной связи в управлении процессом обучения;

- обеспечение студентов постоянной информацией о ближайших и отдаленных целях обучения и степени их достижения;

- обеспечение усвоения содержания учебного материала в соответствии с многокомпонентным составом учебных знаний (теоретические, методологические; оценочные знания и способы учебной деятельности);

- обеспечение оперативности в поиске необходимой учебной информации;

- оптимизация диагностического и контрольно-оценочного инструментария по отношению к существующим критериальным требованиям интегральной десятибалльной системы оценивания и уровням усвоения учебного материала);

- возможность интенсификации профессиональной деятельности преподавателя и учебной (в том числе, и организуемой самостоятельной) деятельности студентов; 
Лозицкий В.Л., Яковлев А.Н. Дидактическая роль электронного учебно-методического...

- адаптивность возможным изменениям структуры и содержания образования, требований и содержания образовательного стандарта, а также программно-планирующей и программно-методической документации.

\section{Выводы}

Применяемый на первой ступени высшего образования ЭУМК по учебной дисциплине «Спортивно-педагогическое совершенствование» позволяет осуществлять эффективное управление учебно-познавательной деятельностью студентов, обеспечивая рациональное сочетание различных ее видов в зависимости от результатов усвоения учебного материала и освоения соответствующих профессиональных психолого-педагогических компетенций. Необходимая эффективность достигается как качеством созданного ЭУМК, так и выполнением соответствующих организационных и методических условий применения, из которых одним из важнейших является практикоориентированность. Именно аспект практической направленности усиливает дидактическую роль предметного электронного учебнометодического комплекса, применимого в учреждении высшего образования на его первой ступени, с учетом специфики осуществляемой учебно-тренировочной и соревновательной деятельности студентов, получающих образование в сфере физической культуры и спорта.

1. Агеев Н.В., Древс Ю.Г. Электронные издания: концепции, создание, использование. М.: МГУП, 2003. 236 с.

2. Архипова А.И., Кочубей И.В., Иус Д.В. Концептуальные подходы к созданию УМК нового поколения [Электронный ресурс]. Кубанский государственный университет. URL: http://www.ieeetclt.org/icalt2002/proceedings/t416_icalt166_End.pdf (дата обращения 16.02.2017).

3. Беспалько В.П. Образование и обучение с участием компьютеров (педагогика третьего тысячелетия). М.: Изд-во Моск. психол.-социал. ин-та; Воронеж : МОДЭК, 2002. 352 c.

4. Воробьев В.А., Сосновский О., Филипцов А.М. Электронный учебно-методический комплекс: разработка и использование в учебном процессе // Высшая школа. 2011. № 1. C. 38-43.

5. Жук А.И., Воротницкий Ю.И., Мандрик П.А. Современный электронный учебнометодический комплекс - основа информационно-образовательной среды вуза // Информатизация образования - 2010: педагогические аспекты создания информациионно-образовательной среды: материалы междунар. науч. конф., Минск, 27-30 октября 2010 г. /редкол.: С.В. Абламейко [и др.]. Минск, 2010. С. 197-201.

6. Кодекс Республики Беларусь об образовании: постановление Совета Республики Национального Собрания Республики Беларусь, 22 декабря 2010 г. № 388-№.4/V // Национальный реестр правовых актов Республики Беларусь. 2011. № 1, 4/6637.

7. Лозицкий В.Л., Яковлев А.Н. Спортивно-педагогическое совершенствование. Электронный учебно-методический комплекс для первой ступени высшего образования / E-Learning «Полесский государственный университет». Учебные курсы 
Moodle [Электронный ресурс]. URL: http://194.158.204.219/moodle (дата обращения 04.03.2017).

8. Макаров А.В. Учебно-методический комплекс: модульная технология разработки: учеб.-метод. пособие. Минск: РИВШ, БГУ, 2002. 118 с.

\section{Транслитерация}

1. Ageev N.V., Drevs Yu.G. Elektronnye izdaniya: kontseptsii, sozdanie, ispol'zovanie. M.: MGUP, 2003. 236 p.

2. Arkhipova A.I., Kochubei I.V., Ius D.V. Kontseptual'nye podkhody k sozdaniyu UMK novogo pokoleniya. Kubanskii gosudarstvennyi universitet. URL: http://www.ieeetclt. org/icalt2002/proceedings/t416_icalt166_End.pdf.

3. Bespal'ko V.P. Obrazovanie i obuchenie s uchastiem komp'yuterov (pedagogika tret'ego tysyacheletiya). M.: Izd-vo Mosk. psikhol.-sotsial. in-ta; Voronezh : MODEK, 2002. 352 p.

4. Vorob'ev V.A., Sosnovskii O. Filiptsov A.M. Elektronnyi uchebno-metodicheskii kompleks: razrabotka i ispol'zovanie v uchebnom protsesse // Vysshaya shkola, 2011, No 1, pp. 38-43.

5. Zhuk A.I., Vorotnitskii Yu.I., Mandrik P.A. Sovremennyi elektronnyi uchebnometodicheskii kompleks - osnova informatsionno-obrazovatel'noi sredy vuza / Informatizatsiya obrazovaniya - 2010: pedagogicheskie aspekty sozdaniya informatsiionnoobrazovatel'noi sredy: materialy mezhdunar. nauch. konf., Minsk, 27-30 oktyabrya 2010 g. / BGU; redkol.: S.V. Ablameiko [i dr.]. Minsk, 2010. Pp. 197-201.

6. Kodeks Respubliki Belarus' ob obrazovanii: postanovlenie Soveta Respubliki Natsional'nogo Sobraniya Respubliki Belarus', 22 dekabrya 2010 g. No 388-№.4/V // Natsional'nyi reestr pravovykh aktov Respubliki Belarus'. 2011. No 1, 4/6637.

7. Lozitskii V.L., Yakovlev A.N. Sportivno-pedagogicheskoe sovershenstvovanie. Elektronnyi uchebno-metodicheskii kompleks dlya pervoi stupeni vysshego obrazovaniya / E-Learning «Polesskii gosudarstvennyi universitet». Uchebnye kursy Moodle. URL: http://194.158.204.219/moodle.

8. Makarov A.V. Uchebno-metodicheskii kompleks: modul'naya tekhnologiya razrabotki: ucheb.-metod. posobie. Minsk: RIVSh, BGU, 2002. 118 p.

\footnotetext{
(C) В.Л. Лозицкий, 2017

(C) А.Н. Яковлев, 2017
}

Для цитирования: Лозицкий В.Л., Яковлев А.Н. Дидактическая роль электронного учебнометодического комплекса на первой ступени высшего образования (на примере учебной дисциплины «Спортивно-педагогическое совершенствование») // Вестник Владивостокского государственного университета экономики и сервиса. 2017. Т. 9, № 3. С. 191-200.

For citation: Lozitsky V.L., Yakovlev A.N. Didactic role of an electronic educational and methodical complex at the first step of the higher education (on the example of the subject matter «Pedagogics and psychology of the higher school»), The Territory of New Opportunities. The Herald of Vladivostok State University of Economics and Service, 2017, Vol. 9, No 1, pp. 191-200.

DOI dx.doi.org/10.24866/VVSU/2073-3984/2017-3/191-200

Дата поступления: 09.06.2017. 